\title{
Cigarette nicotine yields and nicotine intake among Japanese male workers
}

\author{
K Ueda, I Kawachi, M Nakamura, H Nogami, N Shirokawa, S Masui, A Okayama, \\ A Oshima
}

Tobacco Control 2002;11:55-60

\begin{abstract}
Objectives: To analyse brand nicotine yield including "ultra low" brands (that is, cigarettes yielding $\leqslant$ $0.1 \mathrm{mg}$ of nicotine by Federal Trade Commission (FTC) methods) in relation to nicotine intake (urinary nicotine, cotinine and trans-3'-hydroxycotinine) among 246 Japanese male smokers.

Design: Cross sectional study.

Setting: Two companies in Osaka, Japan.

Subjects: 130 Japanese male workers selected randomly during their annual regular health check up and 116 Japanese male volunteers taking part in a smoking cessation programme.

Main outcome measurements: Subjects answered a questionnaire about smoking habits. Following the interview, each participant was asked to smoke his own cigarette and, after extinguishing it, to blow expired air into an apparatus for measuring carbon monoxide concentration. Urine was also collected for the assays of nicotine metabolites.

Results: We found wide variation in urinary nicotine metabolite concentrations at any given nicotine yield. Based on one way analysis of variance (ANOVA), the urinary nicotine metabolite concentrations of ultra low yield cigarette smokers were significantly lower compared to smokers of high $(p=0.002)$ and medium yield cigarettes $(p=0.017)$. On the other hand, the estimated nicotine intake per ultra low yield cigarette smoked $(0.59 \mathrm{mg})$ was much higher than the $0.1 \mathrm{mg}$ indicated by machine.

Conclusions: In this study of Japanese male smokers, actual levels of nicotine intake bore little relation to advertised nicotine yield levels. Our study reinforces the need to warn consumers of inappropriate advertisements of nicotine yields, especially low yield brands.
\end{abstract}

Correspondence to:

Kimiko Ueda, 5-12-50-307

Minoo Minoo-City, Osaka

562-0001, Japan;

kueda@xb4.so-net.ne.jp

Received 27 July 2001

and revision requested

27 September 2001.

Accepted

9 November 2001

M any smokers interpret the information on tar and nicotine yields as shown on cigarette packs as representing the relative harmfulness of the cigarette. ${ }^{12}$ However, because of the well documented effects of compensatory behaviour among users of "low yield" brands, researchers have pointed out that labelling of nicotine/tar yields provides misleading consumer information. ${ }^{3}{ }^{4}$ According to the Federal Trade Commission (FTC) method, the nicotine yield of a cigarette is measured by a smoking machine with a mechanical mouth, drawing a fixed number of standard puffs-a $35 \mathrm{ml}$ volume drawn over 2 seconds repeated every 60 seconds until the cigarette burns down to a predetermined butt length. However, real smokers are not machines, and they respond to the "ultra low" and "low" nicotine yield cigarette by altering their smoking patterns. Studies have shown that smokers who switch from higher to lower yield brands regulate their nicotine intake, by inhaling more deeply, taking more puffs per cigarette, or simply blocking the ventilation holes with their fingers and lips. ${ }^{15-12}$

Not surprisingly, then, studies have shown little correlation between the advertised nicotine yield of cigarettes and the actual concentrations of nicotine or nicotine metabolites in biological samples of users. ${ }^{3413-22}$ Recently, Jarvis and colleagues $^{23}$ reported in a representative British sample of smokers that the nicotine yield of self selected cigarette brands showed little relation with salivary cotinine concentrations. As the authors noted, few of the existing studies included smokers of "ultra low" brands (that is, cigarettes yielding $\leqslant 0.1 \mathrm{mg}$ of nicotine by FTC methods). Data are also sparse in countries outside Britain and the USA, which may differ in their historical pattern of the introduction of "low yield" brands, as well as patterns of smoking habit (for example, depth of inhalation, or the length of the cigarette smoked). Accordingly, we carried out an analysis of brand nicotine yield (including ultra low cigarettes) in relation to nicotine intake among a sample of Japanese male smokers in worksites.

\section{METHODS}

\section{Study population}

We recruited 130 male smokers from a chemical company, and 116 male smokers from a clothing wholesales company, in Osaka, Japan in 1997. In the former site, 130 males were selected from 334 smokers (out of a total 629 male workers) during their annual regular health check up. The subjects were selected through systematic random sampling from a master list of smokers. At the second site (employing 475 male workers), we offered a smoking cessation programme to 135 smokers out of 270 smokers, based on their residential proximity to our clinic. One hundred and sixteen smokers responded to our offer, representing an $85.9 \%$ response rate.

We defined smokers as those who smoked at least 10 cigarettes per day for more than a year. The average (SD) age of participants was 39.7 (9.4) years. The subjects answered a questionnaire about smoking habits. Following the interview, each participant was asked to smoke his own cigarette and, after extinguishing it, to blow expired air into the apparatus for measuring carbon monoxide concentration. Urine was also collected for the assays of nicotine metabolites. These biochemical markers can be regarded as representing usual steady state carbon monoxide and nicotine intake because

Abbreviations: ANOVA, analysis of variance; FTC, Federal Trade Commission; HPLC, high performance liquid chromatography; JT, Japan Tobacco 
Table 1 Selected characteristics of smokers and smoking behaviours according to cigarette nicotine yield

\begin{tabular}{|c|c|c|c|c|c|}
\hline \multirow[b]{2}{*}{ Variables } & \multicolumn{4}{|c|}{ Nicotine yield (mg/cigarette) } & \multirow[b]{2}{*}{$\chi^{2}$} \\
\hline & $\begin{array}{l}\text { Ultra low yield } \\
(0-0.1) \\
n=19\end{array}$ & $\begin{array}{l}\text { Low yield } \\
(0.1-<0.6) \\
n=88\end{array}$ & $\begin{array}{l}\text { Medium yield } \\
(0.6-<1.0) \\
\mathrm{n}=102\end{array}$ & $\begin{array}{l}\text { High yield } \\
(\geqslant 1.0) \\
n=37\end{array}$ & \\
\hline Age, mean (SD) & $44.7(7.5)$ & $39.1(8.6)$ & $39.3(10.0)$ & $40.0(9.8)$ & 39.7 (9.4) (all) \\
\hline Number of years smoked, mean (SD) & $24.4(9.0)$ & $20.0(8.0)$ & $19.6(9.4)$ & $20.7(9.2)$ & 20.3 (8.9) (all) \\
\hline \multicolumn{6}{|l|}{ Inhalation pattern } \\
\hline Light & 15.8 & 5.7 & 7.9 & 2.7 & \\
\hline Medium & 63.2 & 35.2 & 33.7 & 27.0 & $p=0.031$ \\
\hline Deep & 21.0 & 59.1 & 58.4 & 70.3 & \\
\hline \multicolumn{6}{|l|}{ Time to first morning cigarette (\%) } \\
\hline$\leqslant 5$ mins & 15.8 & 26.1 & 33.7 & 48.6 & \\
\hline $5 \mathrm{mins}$ to $\leqslant 30 \mathrm{mins}$ & 47.4 & 43.2 & 43.6 & 35.2 & $\mathrm{p}=0.053$ \\
\hline 30 mins to $<60$ mins & 21.0 & 17.1 & 5.9 & 13.5 & \\
\hline$\geqslant 60$ mins & 15.8 & 13.6 & 16.8 & 2.7 & \\
\hline \multicolumn{6}{|l|}{ Stage of change } \\
\hline Precontemplation & 78.9 & 95.5 & 93.1 & 94.6 & \\
\hline Contemplation & 15.8 & 3.4 & 5.9 & 5.4 & $p=0.260$ \\
\hline Preparation & 5.3 & 1.1 & 1 & 0 & \\
\hline \multicolumn{6}{|l|}{ Quit attempts in the past (\%) } \\
\hline Yes & 78.9 & 54.6 & 43.6 & 29.7 & $p=0.002$ \\
\hline No & 21.1 & 45.4 & 56.4 & 70.3 & \\
\hline
\end{tabular}

these were measured on a day of normal smoking. Informed consent was obtained from each subject.

\section{Ascertainment of smoking habits}

Subjects were asked about their smoking habits using a self administered questionnaire. The questionnaire inquired about the brand and nicotine yield of currently smoked cigarettes, the number of years smoked, the number of cigarettes smoked per day, inhalation pattern, stage of change, time to the first morning cigarette, and quit attempts in the past. The cigarette nicotine yield was obtained by FTC methods, as advertised on the cigarette packet. Nicotine yields were defined according to the following categories: ultra low $(0-0.1 \mathrm{mg})$, low $(>0.1$ and $<0.6 \mathrm{mg})$, medium $(\geqslant 0.6$ to $<1.0 \mathrm{mg})$, and high yield $(\geqslant 1.0 \mathrm{mg})$. The subjects' stage of change was categorised based on Prochaska's transtheoretical stage of change model (precontemplation, contemplation, or preparation). ${ }^{24-26}$ Inhalation pattern was categorised as light/medium/deep, while time to the first morning cigarette was categorised as five minutes or less, $>5$ minutes but $\leqslant 30$ minutes, $>30$ minutes but $\leqslant 1$ hour, and more than 1 hour. Past quit attempts were dichotomised (yes/no).

\section{Biochemical markers}

Physicians, nurses, and counsellors trained in the use of the EC 50 Micro Smokerlyzer (Bedford Instruments, UK) examined the subjects' expired carbon monoxide concentrations. The subjects provided a forced, end expiratory breath sample after a 15 second breath holding procedure. Spot samples of urine were obtained and frozen at $-30{ }^{\circ} \mathrm{C}$ until the time of laboratory analyses. We measured urinary nicotine, cotinine, and trans-3'-hydroxycotinine concentrations with high performance liquid chromatography (HPLC, Waters Corporation, USA). These markers were free forms not including glucuronic acid conjugates. HPLC is the preferred technique to measure cotinine and nicotine in urine. ${ }^{27-29}$ Urinary creatinine concentration was measured by the Jaffe method in a microplate.

All metabolites in a 24 hour urine excretion reflect the amount of nicotine that a person takes in each day. ${ }^{30}$ Trans- $3^{\prime}-$ hydroxycotinine is the major urinary metabolite of nicotine, accounting for an average of $39.1 \%$ of all nicotine metabolites. ${ }^{30}$ Nicotine and cotinine additionally account for an estimated $10.4 \%$ and $13.3 \%$ of urine nicotine metabolites. ${ }^{30}$ Therefore the total concentrations of measured metabolites amount to $62.8 \%$ of the nicotine that a person takes in each day. Our urine samples are from a spot collection. However, since the pattern of metabolism is consistent for an individual over time, ${ }^{30}$ our samples reflect the nicotine daily intake.

\section{Statistical analyses}

We used one way analysis of variance (ANOVA) to test differences in urinary nicotine metabolite concentrations summing up urinary nicotine, cotinine and trans-3'-hydroxycotinine concentrations, urinary cotinine concentrations, expired carbon monoxide concentrations, as well as the daily number of cigarettes, across categories of nicotine yield. Bonferroni multiple comparison tests were carried out. We used $\chi^{2}$ tests to test differences between nicotine yield and categorical smoking variables, including stage of change, inhalation pattern, time to first morning cigarette, and quit attempts in the past. Smokers of cigarette brands with lower nicotine yields are likely to differ from those choosing cigarettes with higher nicotine yields. Accordingly, we also carried out multiple regression analyses to examine the associations between cigarette nicotine yields and urinary nicotine metabolite concentrations, controlling for potential confounding factors such as

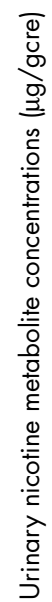

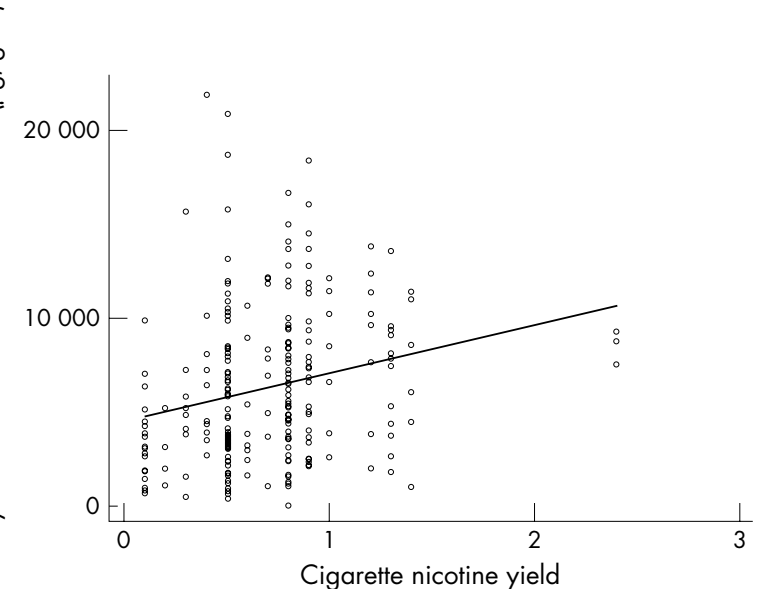

Figure 1 Scatterplot relating cigarette nicotine yields and urinary nicotine metabolite concentrations. Urinary nicotine metabolite concentrations $=4503.2+2557.05$ (nicotine yield) $r=0.23, p<$ 0.001 . gcrea, g creatinine. 


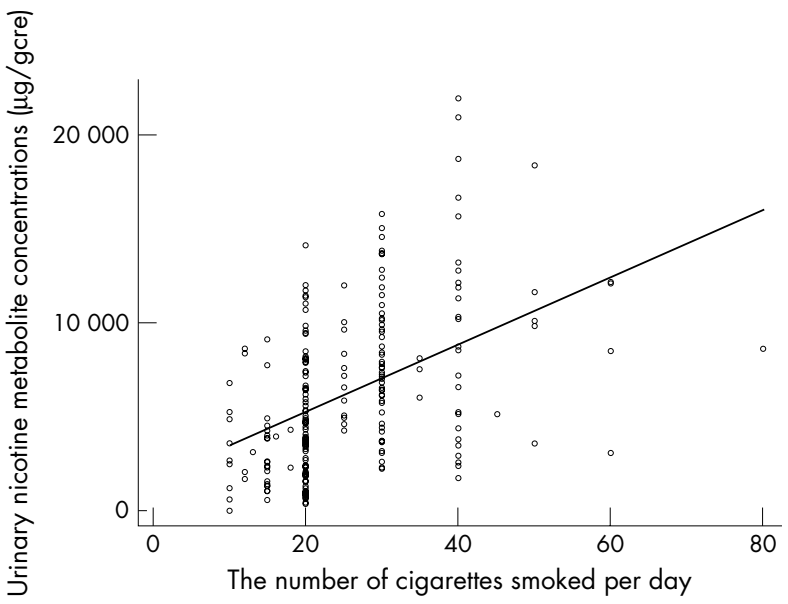

Figure 2 Scatterplot relating the number of cigarettes smoked per day and urinary nicotine metabolite concentrations. Urinary nicotine metabolite concentrations $=1698.99+179.74$ (the number of cigarettes per day); $r=0.46, p<0.001$.

the number of cigarettes smoked per day and inhalation pattern. Statistical significance was determined by two tailed $\mathrm{p} \leqslant 0.05$.

\section{RESULTS}

Our study population included 19 ultra low yield cigarette smokers, 88 low yield cigarette smokers, 102 medium yield cigarette smokers, and 37 high yield cigarette smokers (table
1). In other words, $43.5 \%$ of subjects usually smoked ultra low or low yield cigarettes. Although smokers of ultra low yield brands tended to be somewhat older than the others, the differences were not significant $(\mathrm{F}=2.00, \mathrm{p}=0.114)$, nor were the number of years smoked $(\mathrm{F}=1.62, \mathrm{p}=0.185)$ (table 1$)$. However, differences were found in the stage of change, inhalation pattern, time to the first morning cigarette, and quit attempts in the past. Smokers of ultra low yield cigarettes were less likely to inhale cigarettes deeply $(p=0.031)$. There was also a significant difference between nicotine yield and quit attempts in the past ( $\mathrm{p}=0.002) ; 78.9 \%$ of ultra low yield cigarette smokers had tried to quit smoking in the past compared to only $29.7 \%$ of high yield cigarette smokers. We found no significant differences in the stage of change according to cigarette yield. Consistent with previous reports, ${ }^{24}{ }^{31}{ }^{32}$ the data in table l suggest a lower level of nicotine dependence among users of ultra low and low yield cigarettes, as assessed by longer intervals between waking and smoking the first cigarette of the day, as well as more quit attempts in the past.

As shown in fig 1, we found wide variation in urinary nicotine metabolite concentrations at any given yield of nicotine determined by the FTC method. Although there was a small but significant correlation between brand nicotine yield and urinary nicotine metabolite concentration $(r=0.23$, $\mathrm{p}<0.001$ ), the nicotine yield based on the FTC method could account for only $5.3 \%$ of the variance in metabolite concentrations. We also reanalysed the data after excluding three subjects who used a brand yielding over $2 \mathrm{mg}$ nicotine, because these subjects may have unduly influenced the regression coefficients. However, we obtained virtually the same result $(r=0.23, \mathrm{p}<0.001)$. By contrast, we found a stronger correlation between the number of cigarettes smoked
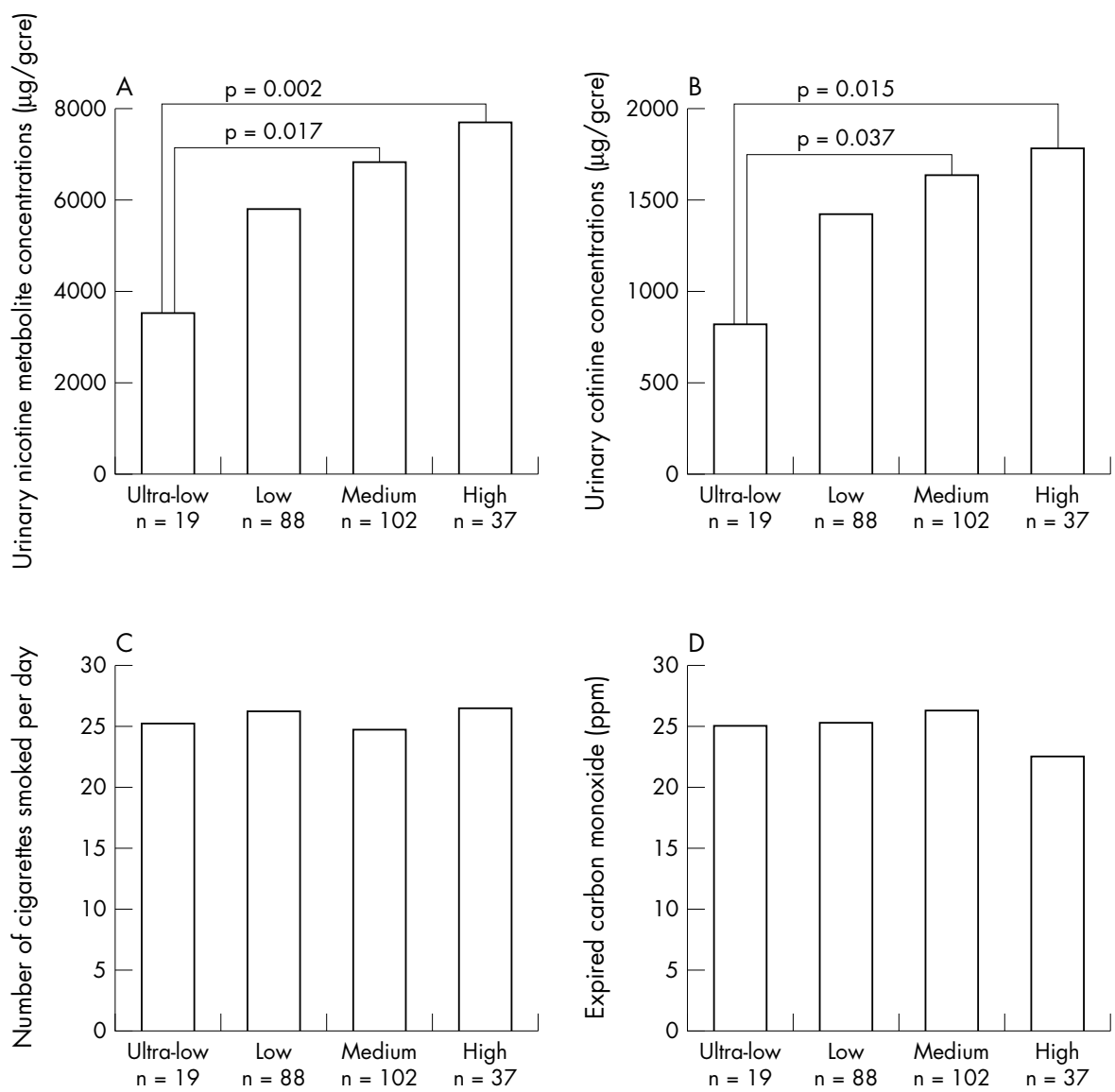

Figure 3 (A) Urinary nicotine metabolite concentrations $(F=4.87, p=0.0026)$; $(B)$ urinary cotinine concentrations $(F=3.45, p=0.0173)$; $(C)$ the number of cigarettes smoked per day $(F=0.43, p=0.734)$; and $(D)$ expired carbon monoxide concentrations $(F=0.93, p=0.425)$ by cigarette nicotine yield groups. 


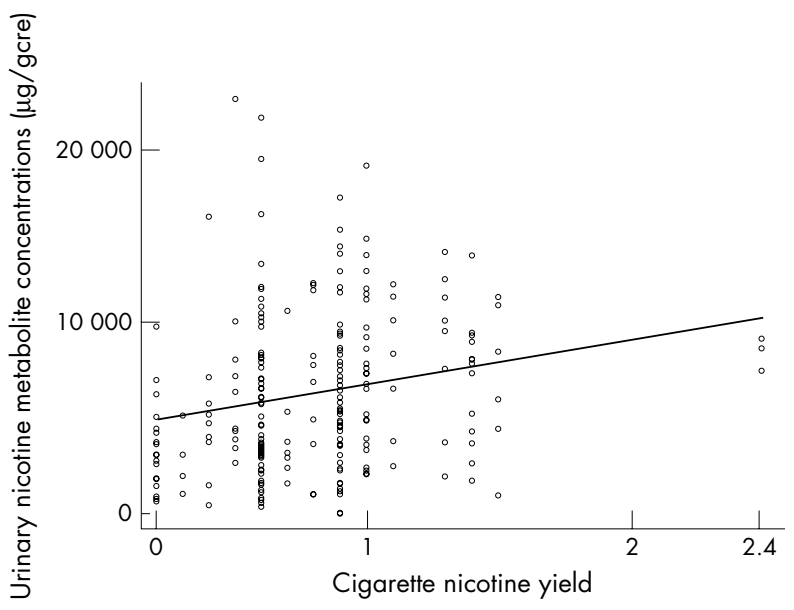

Figure 4 Scatterplot relating cigarette nicotine yields and urinary nicotine metabolite concentrations after control for the number of cigarettes smoked per day and inhalation pattern. Urinary nicotine metabolite concentrations $=4703.51+2344.23$ (nicotine yield) at mean of the number of cigarettes per day and inhalation patterns; $r=0.53, \mathrm{p}<0.001$.

per day and urinary nicotine metabolite concentrations $(r=0.46, \mathrm{p}<0.001)$ (fig 2$)$.

In the one way ANOVA analysis, urinary nicotine metabolite concentrations of ultra low yield cigarette smokers were also significantly different from smokers of high yield cigarettes $(\mathrm{p}=0.002)$ and medium yield cigarettes $(\mathrm{p}=0.017)($ fig $3 \mathrm{~A})$. Urinary cotinine concentrations of ultra low yield cigarette smokers were significantly different from users of high yield cigarettes $(\mathrm{p}=0.015)$ and medium yield cigarettes $(\mathrm{p}=0.037)$ (fig $3 \mathrm{~B})$. We found no group differences in the number of cigarettes per day and expired carbon monoxide concentrations (fig 3C, D).

Self reported inhalation pattern was positively related to urinary nicotine metabolite concentrations $(r=0.20$, $p=0.002$ ), even though self reported inhalation is poorly correlated with objective inhalation measures. ${ }^{33}{ }^{34}$ In multiple regression adjusting for confounders such as the number of cigarettes smoked per day and inhalation pattern, we found that the slope relating brand nicotine yield to urinary nicotine metabolite concentrations was shallower (fig 4), though it remained significant $(\mathrm{p}<0.001)$. The incremental proportion of variance explained by the brand nicotine yield after adjustment for confounders was $4.1 \%$.

According to Benowitz and Jacob, every $1000 \mu \mathrm{g} / \mathrm{g}$ creatinine of urinary nicotine and metabolite excretion over 24 hours is equivalent to a daily intake of $3.549 \mathrm{mg}$ of nicotine. ${ }^{30}$
We estimated the daily nicotine intake and nicotine intake per cigarette smoked using this approximation (table 2). Though the estimated nicotine intake per ultra low yield cigarette was lower than other brands, the estimated nicotine intake $(0.59 \mathrm{mg})$ was much higher than the value of $0.1 \mathrm{mg}$ indicated by the FTC method. Similarly, the estimated nicotine intake per cigarette for other brands bore no relation to cigarette yields advertised. We caution, however, that this part of the analysis is based on the use of an average conversion factor to estimate daily nicotine intake from urinary metabolite profiles. Growing evidence suggests that smokers metabolise, transport, and uptake nicotine at different rates, and furthermore, there may be genetic differences between Japanese smokers and Western populations.

\section{DISCUSSION}

Our findings in Japanese male smokers reinforce the point that the nicotine yield advertised on cigarette packets bear little relation with actual nicotine exposure. Low yield nicotine cigarettes were developed for the first time in the USA in 1964 as a "safe" alternative to conventional cigarettes. At the same time, Japan Tobacco Inc (JT) also moved to produce lower nicotine/tar cigarettes. In 1988, JT started to sell ultra low cigarettes. Since 1990, the Japanese Ministry of Finance has required tobacco companies to indicate the nicotine/tar yield on cigarette packets, according to the FTC method. In response, the strategy of cigarette manufacturers has been to shift production to lower nicotine/tar yield cigarettes, and to promote them as cigarettes with lower health risk. JT reported that of all the domestic brands that it produced in 2001, 13\% and $27 \%$ of cigarettes were, respectively, ultra low $(0-0.1 \mathrm{mg})$ and low ( $>0.1$ and $<0.6 \mathrm{mg}$ ) nicotine yield.$^{35}$ Domestically produced cigarettes accounted for $75 \%$ of the Japanese market share in 2000. The market share of imported cigarettes has risen rapidly from $2.4 \%$ in 1985 , to $25 \%$ in 2001 following market liberalisation. ${ }^{36}{ }^{37}$ These imported cigarettes also heavily emphasise low nicotine/tar yield brands. According to the Tobacco Institute of Japan, ultra low and low yield cigarettes accounted for just $0.2 \%$ and $1.2 \%$, respectively, of the top 100 popular brands in 1990 . On the other hand, the corresponding figures had risen to $12.6 \%$ and $32.7 \%$ by 2000 .

Our study indicated $43.5 \%$ of subjects smoked ultra low or low nicotine yield cigarettes. This proportion is considerably higher than that in England (34.2\%) or the USA. ${ }^{23}$ At the same time, the smoking rate among Japanese males remains relative high $(53.5 \% \text { in } 2000)^{38}$ compared to England (29\%) and the USA $(25 \%) .{ }^{39}$ It is likely that ultra low and low yield cigarette smokers use these brands as an alternative to quitting altogether. ${ }^{1}$ Low yield cigarettes are a threat to public health to the extent that they distort smokers' perceptions of health risks, and reduce their intentions to quit. ${ }^{1}$

\begin{tabular}{|c|c|c|c|c|c|}
\hline \multirow[b]{2}{*}{ Variables } & \multicolumn{4}{|c|}{ Nicotine yield ( $\mathrm{mg} /$ cigarette) } & \multirow[b]{2}{*}{ ANOVA } \\
\hline & $\begin{array}{l}\text { Ultra low yield } \\
(0-0.1) \\
\mathrm{n}=19\end{array}$ & $\begin{array}{l}\text { Low yield } \\
(0.1-<0.6) \\
n=88\end{array}$ & $\begin{array}{l}\text { Medium yield } \\
(0.6-<1.0) \\
\mathrm{n}=102\end{array}$ & $\begin{array}{l}\text { High yield } \\
(\geqslant 1.0) \\
n=37\end{array}$ & \\
\hline $\begin{array}{l}\text { Urinary nicotine metabolite concentrations ( } \mu \mathrm{g} / \mathrm{g} \text { creatinine) }{ }^{*} \text {, } \\
\text { mean (SD) }\end{array}$ & $3582(2350)$ & $5931(4408)$ & $6616(4093)$ & $7716(3491)$ & $\begin{array}{l}F=4.87 \\
p=0.0026\end{array}$ \\
\hline Estimated daily nicotine intake (mg), mean (SD) & $15.8(10.7)$ & $26.0(23.8)$ & $31.8(27.2)$ & $34.5(19.4)$ & $\begin{array}{l}F=3.45 \\
p=0.0174\end{array}$ \\
\hline Self reported daily cigarette consumption, mean (SD) & $25.3(9.0)$ & $26.7(10.8)$ & $25.1(11.6)$ & $26.5(8.3)$ & $\begin{array}{l}F=0.43 \\
p=0.734\end{array}$ \\
\hline Estimated intake of nicotine $(\mathrm{mg})$ per cigarette smoked, mean (SD) & $0.59(0.32)$ & $1.01(0.86)$ & $1.27(0.82)$ & $1.36(0.82)$ & $\begin{array}{l}F=5.5 \\
p=0.0011\end{array}$ \\
\hline
\end{tabular}

*Urinary nicotine metabolite concentrations were defined as summing up urinary nicotine, cotinine, and trans-3'-hydroxycotinine concentrations. 
It is well known that smokers behaviourally compensate their smoking patterns to regulate their daily nicotine intake. ${ }^{80-45}$ Studies of smokers switching to lower yield cigarettes showed that they tend to increase the volume per puff, $^{57}$ and the depth of inhalation. ${ }^{6}$ Similar findings have been obtained among stable smokers of lower yield cigarettes. ${ }^{90}$ In our study, we found no group differences in expired carbon monoxide concentrations, supporting the presence of compensation. However, in contrast to Jarvis and colleagues, ${ }^{23}$ we found significantly lower concentrations of nicotine metabolites among users of ultra low brands. The reasons for the difference between our carbon monoxide and nicotine metabolite findings are not clear. Nor can we say whether the observed association between advertised nicotine yield and intake is wholly due to self selection or to some real (but small) effect of yield on intake.

What we can say is that the yield advertised on the cigarette packs grossly underestimated actual nicotine intakes. The estimated nicotine intake per ultra low yield cigarette was six times higher than that indicated by machine method. Djordjevic and colleagues in the USA also found that the FTC protocol underestimated the exposure not only to nicotine but also to other components of cigarette smoke that affect lung cancer risk such as tar and benzo[a]pyrene and 4-(methylnitrosamino)-1-(3-pyridyl)-1-butanone. ${ }^{46}$ The health benefit of smoking low yield cigarettes is therefore far from established. Indeed, some studies suggest an increase in adenocarcinoma associated with the increased use of these cigarettes. ${ }^{47}$

Urinary cotinine is a widely used measured of nicotine intake 568131421 48-53 We used spot urine samples to avoid burden on our subjects during working hours. The pattern of nicotine metabolism is consistent for an individual over time, ${ }^{30}$ so that our spot samples may be reasonably assumed to reflect daily nicotine intake. Nicotine is extensively metabolised and excreted into urine as several nicotine metabolites over a day. ${ }^{30}$ The percent of cotinine converted to trans-3'hydroxycotinine varies among individuals. ${ }^{30}$ However, our measurement of total nicotine metabolite concentrations combined nicotine, cotinine and trans-3'-hydroxycotinine concentrations, and should reflect overall nicotine intake well. On the other hand, we did not take account of individual differences in percent conversion of nicotine (perhaps related to genetic or age differences in metabolic activity), ${ }^{30}$ or differences in urine $\mathrm{pH}^{54}$

Socioeconomic status might have been a potential confounding factor in our analyses, although we did not measure it. A study in Britain found that smokers of lower nicotine yield cigarettes compared to other types of cigarettes tended to be better educated, own a car, own their homes, and to not have a manual occupation. ${ }^{23}$ The socioeconomic status of workers in our two work places (a chemical and clothing wholesales company) could be described as more middle class. Although they were not representative of the Japanese male workforce, they were similar to the overall population of Japanese adult males with respect to their smoking rates. The smoking prevalence at our two work sites $(53.1 \%$ and $56.8 \%$ ) was quite comparable to the national figure for Japanese males $(53.5 \%)$

\section{ACKNOWLEDGMENTS}

This work was supported in part by the Grant-in Aid for Cancer Research (9-5) from the Ministry of Health and Welfare. We thank Dr Makoto Watanabe, Health Science, Shiga University of Medical Science, and Dr Masashi Nakagawa, Osaka Medical Center for Cancer and Cardiovascular Diseases, for collecting the data from subjects.

\section{Authors' affiliations}

K Ueda, Master of Public Health Program, Harvard School of Public Health, Boston, Massachusetts, USA

\section{What this paper adds}

Previous studies have found little relation between the advertised nicotine yield of cigarettes and concentrations of nicotine metabolites measured in smokers. However, few studies have included smokers of "ultra low" brands (cigarettes yielding $\leqslant 0.1 \mathrm{mg}$ of nicotine by FTC methods). Data are also sparse in countries outside Britain and the USA.

We conclude that, based on the concentrations of urinary biomarkers, the FTC nicotine yields in cigarette smoke were not equivalent to nicotine exposure at any advertised yield level. Moreover, ultra low and low yield cigarettes may not reduce the risk of ill health.

I Kawachi, Department of Health and Social Behavior, Harvard School of Public Health

M Nakamura, N Shirokawa, S Masui, Department of Health

Promotion and Education, Osaka Medical Center for Health Science and Promotion, Osaka, Japan

H Nogami, Environmental Research Division, Osaka Prefectural Institute of Public Health

A Okayama, Department of Hygiene and Preventive Medicine, Iwate

Medical University School of Medicine, Japan

A Oshima, Department of Cancer Control and Statistics, Osaka Medical Center for Cancer and Cardiovascular Diseases

\section{REFERENCES}

1 Kozlowski LT, Goldberg ME, Yost BA, et al. Smokers' misperceptions of light and ultra-light cigarettes may keep them smoking. Am J Prev Med 1998:15:9-16.

2 Kozlowski LT, Goldberg ME, Yost BA, et al. Smokers are unaware of the filter vents now on most cigarettes: results of a national survey. Tobacco Control 1996;5:265-70.

3 Benowitz NL, Hall SM, Herning RI, et al. Smokers of low-yield cigarettes do not consume less nicotine. N Engl J Med 1983;309:139-42.

4 Russell MA, Jarvis $M$, lyer $R$, et al. Relation of nicotine yield of cigarettes to blood nicotine concentrations in smokers. BM 1980;280:972-6.

5 Armitage AK, Alexander J, Hopkins R, et al. Evaluation of a low to middle tar/medium nicotine cigarette designed to maintain nicotine delivery to the smoker. Psychopharmacology (Berl) 1988;96:447-53.

6 Tobin MJ, Sackner MA. Monitoring smoking patterns of low and high tar cigarettes with inductive plethysmography. Am Rev Respir Dis 1982; 126:258-64

7 Zacny JP, Stitzer ML. Cigarette brand-switching: effects on smoke exposure and smoking behavior. J Pharmacol Exp Ther 1988;246:619-27.

8 Kolonen S, Tuomisto J, Puustinen P, et al. Smoking behavior in low-yield cigarette smokers and switchers in the natural environment. Pharmacol Biochem Behav 1991;40:177-80.

9 Diordjevic MV, Stellman SD, Zang E. Doses of nicotine and lung carcinogens delivered to cigarette smokers. J Natl Cancer Inst 2000;92:106-11.

10 Kozlowski LT, Heatherton TF, Frecker RC, et al. Self-selected blocking of vents on low-yield cigarettes. Pharmacol Biochem Behav 1989:33:815-9.

11 Kolonen S, Tuomisto J, Puustinen P, et al. Puffing behavior during the smoking of a single cigarette in a naturalistic environment. Pharmacol Biochem Behav 1992;41:701-6.

12 Kozlowski LT, Pope MA, Lux JE. Prevalence of the misuse of ultra-low-tar cigarettes by blocking filter vents. Am J Public Health 1988;78:694-5.

13 Gori GB, Lynch CJ. Analytical cigarette yields as predictors of smoke bioavailability. Regul Toxicol Pharmacol 1985;5:314-26.

14 Kolonen SA, Puhakainen EV. Assessment of the automated colorimetric and the high-performance liquid chromatographic methods for nicotine intake by urine samples of smokers' smoking low- and medium-yield cigarettes. Clin Chim Acta 1991:196:159-66.

15 Russell MA, Jarvis M, Feyerabend C, et al. Reduction of tar, nicotine and carbon monoxide intake in low tar smokers. J Epidemiol Community Health 1986;40:80-5

16 Gori GB, Lynch CJ. Smoker intake from cigarettes in the 1-mg Federal Trade Commission tar class. Regul Toxicol Pharmacol 1983:3:1 10-20.

17 Woodward M, Tunstall-Pedoe H. Do smokers of lower tar cigarettes consume lower amounts of smoke components? Results from the Scottish Heart Health Study. Br J Addict 1992;87:921-8.

18 Woodward $M$, Tunstall-Pedoe $H$. Self-titration of nicotine: evidence from the Scottish Heart Health Study. Addiction 1993;88:821-30.

19 Ebert RV, McNabb ME, McCusker KT, et al. Amount of nicotine and carbon monoxide inhaled by smokers of low-tar, low-nicotine cigarettes. JAMA 1983;250:2840-2.

20 Coultas DB, Stidley CA, Samet JM. Cigarette yields of tar and nicotine and markers of exposure to tobacco smoke. Am Rev Respir Dis $1993 ; 148: 435-40$ 
21 Mohtashamipur E, Norpoth K, Lieder F. Urinary excretion of mutagens in smokers of cigarettes with various tar and nicotine yields, black tobacco, and cigars. Cancer Lett 1987;34:103-12.

22 Benowitz NL, Jacob P 3rd, Yu L, et al. Reduced tar, nicotine, and carbon monoxide exposure while smoking ultralow- but not low-yield cigarettes. JAMA 1986;256:241-6.

23 Jarvis MJ, Boreham R, Primatesta $P$, et al. Nicotine yield from machine-smoked cigarettes and nicotine intakes in smokers: evidence from a representative population survey. J Natl Cancer Inst 2001:93:134-8.

24 DiClemente CC, Prochaska JO, Fairhurst SK, et al. The process of smoking cessation: an analysis of precontemplation, contemplation, and preparation stages of change. J Consult Clin Psychol 1991;59:295-304.

25 Prochaska JO, Velicer WF, DiClemente CC, et al. Measuring processes of change: applications to the cessation of smoking. J Consult Clin Psychol 1988;56:520-8.

26 Prochaska JO, DiClemente CC. Stage and processes of self-change of smoking: toward an integrative model of change. J Counsult Clin Psychol 1983;51:390-5

27 Parviainen MT, Barlow RD. Assessment of exposure to environmental tobacco smoke using a high-performance liquid chromatographic method for the simultaneous determination of nicotine and two of its metabolites in urine. J Chromatogr 1988;431:216-21.

28 Watson ID. Rapid analysis of nicotine and cotinine in the urine of smokers by isocratic high-performance liquid chromatography. J Chromatogr 1977; 143:203-6.

29 Oddoze C, Pauli AM, Pastor J. Rapid and sensitive high-performance liquid chromatographic determination of nicotine and cotinine in nonsmoker human and rat urines. J Chromatogr B Biomed Sci Appl 1998:708:95-101.

30 Benowitz NL, Jacob P 3rd, Fong I, et al. Nicotine metabolic profile in man: comparison of cigarette smoking and transdermal nicotine. $J$ Pharmacol Exp Ther 1994;268:296-303

31 Ueda K, Nakamura M, Shirokawa N, et al. The relationship between stages and biochemical markers of smoking. Workplace-based cross-sectional and longitudinal studies. Nippon Koshu Eisei Zasshi 2000;47:783-91.

32 Pallonen UE, Fava JL, Salonen JT, et al. Readiness for smoking change among middle-aged finnish men. Addict Behav 1992;17:415-23.

33 Tobin MJ, Jenouri G, Sackner MA. Subjective and objective measurement of cigarette smoke inhalation. Chest 1982;82:696-700.

34 Adams L, Lee C, Rawbone R, et al. Patterns of smoking: measurement and variability in asymptomatic smokers. Clin Sci (Colch) 1983:65:383-92.

35 http://www.jtnet.ad.jp/WWW/JT/JTI/outline/tobacco/kamimaki-1.html - http://www.jtnet.ad.jp/WWW/JT/JTI/outline/tobacco/ kamimaki-13.html, 5th May 2001

36 http://www.jtnet.ad.jp/WWW/JT/JTI/outline/tobacco/hancaisuJ.html, 5th May 2001
37 Honio K, Kawachi I. Effects of market liberalisation on smoking in Japan. Tobacco Control 2000;9:193-200.

38 2000-nen Zenkoku Tobaco-kitsuensyaritsucyosa: Danjo-kei de 32.9\% [2000 National Cigarette smoking prevalence surveys: prevalence is $32.9 \%$ ]. Japan Tobacco. Press release. No.14, October $26,2000$.

39 Corrao MA, Guindon GE, Sharma N, et al, eds. Tobacco control country profiles. Atlanta, Georgia: American Cancer Society, 2000

40 Hee J, Callais F, Momas I, et al. Smokers' behaviour and exposure according to cigarette yield and smoking experience. Pharmacol Biochem Behav 1995:52:195-203.

41 Herning RI, Jones RT, Benowitz NL, et al. How a cigarette is smoked determines blood nicotine levels. Clin Pharmacol Ther 1983;33:84-90.

42 Fagerstrom KO. Effects of a nicotine-enriched cigarette on nicotine titration, daily cigarette consumption, and levels of carbon monoxide, cotinine, and nicotine. Psychopharmacology (Berl) 1982;77: 164-7.

43 Haley NJ, Sepkovic DW, Hoffmann D, et al. Cigarette smoking as a risk for cardiovascular disease. Part VI. Compensation with nicotine availability as a single variable. Clin Pharmacol Ther 1985;38:164-70.

44 Henningfield JE. Nicotine medications for smoking cessation. N Engl J Med 1995:333:1196-203.

45 Gori GB, Benowitz NL, Lynch CJ. Mouth versus deep airways absorption of nicotine in cigarette smokers. Pharmacol Biochem Behav 1986;25:1181-4.

46 Diordjevic MV, Stellman SD, Zang E. Doses of nicotine and lung carcinogens delivered to cigarette smokers. J Natl Cancer Inst 2000;92:106-11

47 Franceschi S, Bidoli E. The epidemiology of lung cancer. Ann Oncol 1999;10(suppl 5):S3-6.

48 Kawano $\mathbf{H}$, Inamasu $T$, Ishizawa $M$, et al. Mutagenicity of urine from young male smokers and nonsmokers. Int Arch Occup Environ Health 1987;59:1-9.

49 Jarvis $M$, Tunstall-Pedoe H, Feyerabend C, et al. Biochemical markers of smoke absorption and self reported exposure to passive smoking. $J$ Epidemiol Community Health 1984;38:335-9.

50 Thompson SG, Stone R, Nanchahal K, et al. Relation of urinary cotinine concentrations to cigarette smoking and to exposure to other people's smoke. Thorax 1990;45:356-61.

51 Vine MF, Hulka BS, Margolin BH, et al. Cotinine concentrations in semen, urine, and blood of smokers and nonsmokers. Am J Public Health 1993;83:1335-8.

52 Willers S, Attewell R, Bensryd I, et al. Exposure to environmental tobacco smoke in the household and urinary cotinine excretion, heavy metals retention, and lung function. Arch Environ Health 1992:47:357-63.

53 Rickert WS, Robinson JC, Young JC, et al. A comparison of the yields of tar, nicotine, and carbon monoxide of 36 brands of Canadian cigarettes tested under three conditions. Prev Med 1983;12:682-94.

54 Benowitz NL, Kuyt F, Jacob P 3rd, et al. Cotinine disposition and effects Clin Pharmacol Ther 1983:34:604-11.

\section{New TC online submission and review system}

We are pleased to inform authors and reviewers that Tobacco Control is now using a new online submission and review system. Developed by Highwire Press (CA, USA), Bench>Press is a fully integrated electronic system which utilises the web to allow rapid and efficient submission of manuscripts. It also allows the peer review process to be conducted entirely online. The main aim is to speed up the frequently frustrating progress from submission to publication.

Authors can submit their manuscript in any standard word processing software. Standard graphic formats acceptable are: .jpg, .tiff, .gif, and eps (however multipage powerpoint files are NOT acceptable). The text and graphic files are automatically converted to PDF for ease of distribution and reviewing purposes. Authors are asked to approve their submission before it formally enters the reviewing process. On approval by the authors, the submission is passed to the editor and/or reviewers via the web. All transactions are secure.

To access the system click on "SUBMIT YOUR MANUSCRIPT HERE" on the Tobacco Control homepage: www.tobaccocontrol.com, or access Bench>Press directly at http://submit-tc.bmijournals.com/.

We are very excited at this new development and I would encourage authors and reviewers to use the online system where possible. It really is simple to use and should be a big improvement on the current peer review process. If required, full instructions can be found on Bench>Press http://submit-tc.bmijournals.com/, and TC online at www.tobaccocontrol.com.

Please contact Natalie Davies, Project Manager (ndavies@bmigroup.com) for further information.

Simon Chapman Editor 